\title{
Emerging role of the peroxisome proliferator-activated receptor-gamma in hepatocellular carcinoma
}

REVIEW

This article was published in the following Dove Press journal:

Journal of Hepatocellular Carcinoma

26 August 2014

Number of times this article has been viewed

\section{Hui-Tzu Hsu' \\ Chin-Wen Chi ${ }^{1,2}$ \\ 'Department and Institute of Pharmacology, School of Medicine, National Yang-Ming University, Taipei, Taiwan; ${ }^{2}$ Department of Medical Research, Taipei Veterans General Hospital, Taipei, Taiwan}

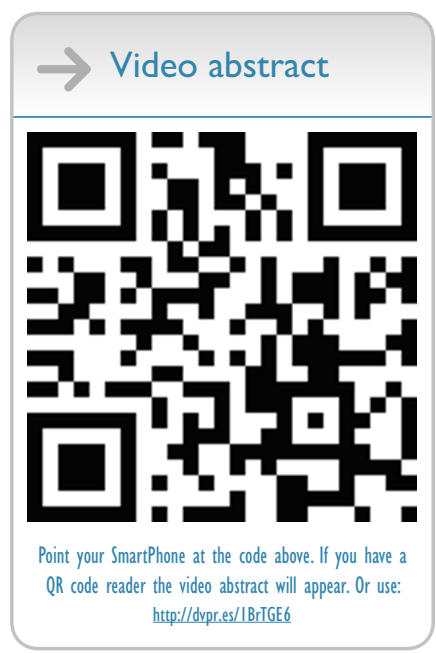

Correspondence: Chin-Wen Chi

Department of Medical Research, Taipei Veterans General Hospital, No 322,

Sec 2, Shipai Road, Taipei II2, Taiwan

Tel +88622875 7627

Fax $+88622875 \quad 1562$

Email cwchi@vghtpe.gov.tw

\begin{abstract}
Hepatocellular carcinoma (HCC) is the major leading cause of cancer death worldwide. Hepatitis B virus, hepatitis $\mathrm{C}$ virus, alcohol consumption, non-alcoholic fatty liver disease, and diabetes are the major risks for developing HCC. Until now, recurrence and metastasis are the major cause of death in HCC patients. Therefore, identification of new effective molecular targets is an urgent need for treatment of HCC. Peroxisome proliferator-activated receptor $\gamma(\operatorname{PPAR} \gamma)$ is a ligand-activated nuclear receptor which could be activated by PPAR $\gamma$ agonists such as thiazolidinediones, and natural PPAR $\gamma$ ligand (such as 15 -deoxy- $\Delta 12,14$ prostaglandin $\mathrm{J}_{2}, 15 \mathrm{~d}-\mathrm{PGJ}_{2}$ ). Increasing in vitro and in vivo evidence has demonstrated that PPAR $\gamma$ agonists exhibit an inhibitory role on tumor cell growth, migration, and invasion, suggesting that PPAR $\gamma$ activation may play an important role in the regulation of growth of HCC. It has been reported that PPAR $\gamma$ activation by thiazolidinediones or overexpression of PPAR $\gamma$ by virus-mediated gene transfer has shown growth inhibitory effects in hepatoma cells, but the expression level of PPAR $\gamma$ in HCC tissues still remains conflicting. Notably, a novel PPAR $\gamma$ agonist, honokiol, has recently been found to activate the PPAR $\gamma / \mathrm{RXR}$ heterodimer, and has also exhibited significant anti-cancer effects in hepatoma cells. In the present review, we summarized studies on the role and the molecular regulation of PPAR $\gamma$ in HCC development in vitro and in vivo. PPAR $\gamma$ has the potential to be a therapeutic target for future treatment of HCC.
\end{abstract}

Keywords: hepatocellular carcinoma, peroxisome proliferator-activated receptor $\gamma$, thiazolidinediones, honokiol, microRNA

\section{Hepatocellular carcinoma}

Liver cancer is the second leading cause of cancer death in males worldwide. ${ }^{1}$ Hepatocellular carcinoma (HCC) is the major subtype among liver cancers. Eighty percent of HCC occurred in Asia and Africa, where the high prevalence of hepatitis $\mathrm{B}$ virus (HBV) and hepatitis $\mathrm{C}$ virus (HCV) infections is highly correlated to inflammation of the liver, leading to the subsequent development of HCC. ${ }^{2}$ Additionally, patients with diabetes not only have an increased risk of $\mathrm{HCC}^{3}$ but also have a poorer survival rate after curative therapy for $\mathrm{HCC}^{4}$ On the other hand, obesity, dietary aflatoxin $\mathrm{B} 1$ exposure, and excessive alcohol consumption are also major risk factors for the development of HCC. ${ }^{5,6}$ Moreover, liver cirrhosis is a well-known risk factor for HCC (Figure 1). Inflammatory cytokine-induced signaling plays an important role in liver cirrhosis ${ }^{7}$ and carcinogenesis of $\mathrm{HCC}^{8}$ In western countries, $30 \%-40 \%$ of HCC cases are attributable to non-alcoholic fatty liver disease (NAFLD) or metabolic syndrome. ${ }^{9,10}$ Until now, surgical resection has been the best treatment for HCC, especially for patients with a tumor $\leq 5 \mathrm{~cm}$ in diameter. In addition, liver transplantation provides another option 


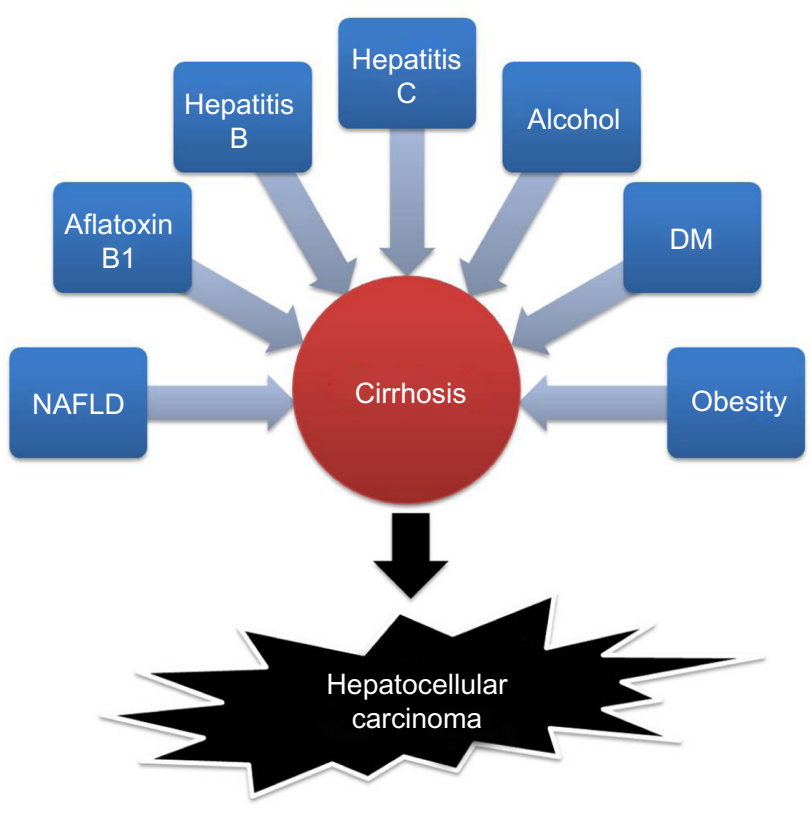

Figure I Risk factors for hepatocellular carcinoma development. Abbreviations: NAFLD, non-alcoholic fatty liver disease; DM, diabetes mellitus.

for curing HCC but is limited by the number of available donors. ${ }^{11}$ Recurrence and metastasis are the major causes of increased mortality after treatments such as transcatheter arterial chemoembolization, chemotherapy, and radiotherapy. ${ }^{12,13}$ Therefore, understanding the pathogenesis and development of HCC can help us to identify new therapeutic targets and to develop new therapeutic agents or strategies to increase the effectiveness of treatment for patients with HCC.

Targeted therapy has significantly advanced treatment of HCC as chemotherapy for HCC has been met with limited success for many years as a result of high expression of multidrug resistance in $\mathrm{HCC} .{ }^{14,15}$ In the past few years, a small multikinase (vascular endothelial growth factor [VEGF] receptor, platelet-derived growth factor receptor, and Raf kinases) inhibitor, sorafenib (Nexavar ${ }^{\circledR}$, Bayer and Onyx Pharmaceuticals, South San Francisco, California, USA), was the first targeted therapeutic agent that showed a significant increase in the survival of HCC patients. ${ }^{16-18}$ It has long been known that HCC tissue has VEGF expression. ${ }^{19}$ Most recently, it has been reported that decreased plasma VEGF, a major mediator of angiogenesis in $\mathrm{HCC}$, with a level $>5 \%$ at 8 weeks after sorafenib treatment was highly associated with favorable overall survival in advanced HCC patients. ${ }^{20}$ It is interesting that the VEGF level in these patients showed an increase at 4 weeks after sorafenib treatment and this may have resulted from sorafenib-induced hypoxia in tumor cells leading to increased secretion of VEGF. However, only those patients who had a $>5 \%$ decreased VEGF level at 8 weeks after starting sorafenib treatment had favorable overall survival. The mechanism for this observation is not clear but it is likely that decreased secretion of VEGF from tumor cells may be important. This report demonstrated that sequential measurement of VEGF is important for the prediction of sorafenib treatment's efficacy in advanced HCC patients. ${ }^{20}$

In addition to targeted therapy, there are many antiinflammatory herbal medicines such as baicalein, ${ }^{21}$ curcumin, ${ }^{22}$ quercetin, ${ }^{23}$ resveratrol, ${ }^{24}$ and honokiol ${ }^{25-27}$ which also exhibited an inhibitory role on cell growth, migration, and invasion of HCC. ${ }^{28}$ Recently, a natural biphenolic compound honokiol was found to function as a novel non-adipogenic peroxisome proliferator-activated receptor $\gamma$ (PPAR $\gamma$ ) agonist of adipocyte. ${ }^{29}$ Notably, PPAR $\gamma$ is not only involved in anti-inflammatory pathways, but also exerted cell growth inhibition and antimetastasis in HCC. ${ }^{30}$ Moreover, synthetic PPAR $\gamma$ agonists, thiazolidinediones (TZDs), also showed anti-tumor effects on HCC. ${ }^{30}$ Consequently, the function, molecular pathways, and herbal medicine involved in PPAR $\gamma$ signaling pathways will be novel targets for potential treatment of HCC.

\section{Molecular structure of PPAR $\gamma$}

PPAR $\gamma$ is a ligand-activated nuclear hormone receptor. Once ligand binding has occurred, PPAR $\gamma$ heterodimerizes with retinoid $\mathrm{X}$ receptor (RXR) and this complex subsequently recruits coactivators or corepressors, to regulate the target genes related to lipid and glucose metabolisms as well as inflammation. ${ }^{31}$ Human PPAR $\gamma$ protein is composed of four functional domains including an N-terminal A/B domain (containing activation function 1, AF1), a DNA-binding domain containing two zinc fingers, a hinge domain, and a $\mathrm{C}$-terminal ligand binding domain (LBD) (containing AF2) (Figure 2). ${ }^{32}$ The A/B domain is associated with ligand-independent

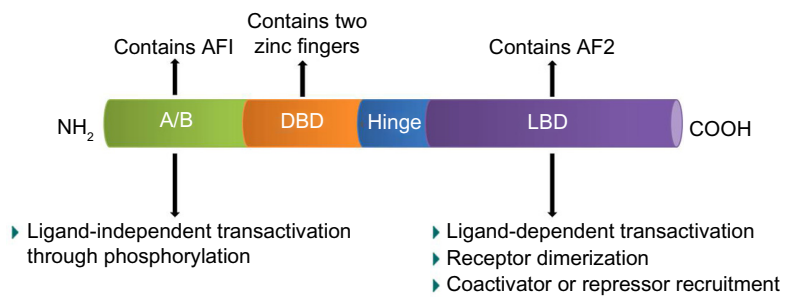

Figure 2 Schematic diagram of the functional domain of PPAR $\gamma$.

Notes: PPAR $\gamma$ is composed of four different domains. The $\mathrm{N}$-terminal A/B domain (containing activation function $\mathrm{I}$ ) is responsible for ligand-independent transactivation through phosphorylation. The DNA-binding domain contains two zinc fingers. The hinge domain allows independent movement of the next and last domain of $\operatorname{PPAR} \gamma$ (ligand binding domain). The C-terminal ligand binding domain (containing activation function 2) is responsible for ligand-dependent transactivation and is the crucial regulatory domain for the heterodimerization which is subsequently capable of recruiting coactivators and corepressors necessary for the transcriptional regulation. Abbreviations: $A F$, activation function; DBD, DNA-binding domain; LBD, ligandbinding domain; PPAR, peroxisome proliferator-activated receptor. 
transactivation through phosphorylation. ${ }^{33}$ This phosphorylation decreased transcriptional activity of PPAR $\gamma$ by mitogen-activated protein kinase ${ }^{34}$ and $5^{\prime}$-AMP-activated protein kinase to repress ligand-dependent effects including lipid and glucose metabolisms. ${ }^{35}$ The LBD is responsible for ligand-dependent transactivation and is the crucial regulatory domain for the heterodimerization which is capable of recruiting coactivators and corepressors necessary for the subsequent transcriptional regulation (Figure 3). ${ }^{36}$ PPAR $\gamma$ can be activated by the natural ligands such as 15-deoxy$\Delta$ 12,14-prostaglandin $\mathrm{J}_{2}\left(15 \mathrm{~d}-\mathrm{PGJ}_{2}\right),{ }^{37}$ lysophosphatidic acid, ${ }^{38}$ and nitrolinoleic acid. ${ }^{39}$ PPAR $\gamma$ can also be activated by synthetic ligands including the TZDs such as rosiglitazone, pioglitazone, ciglitazone, and troglitazone..$^{40,41}$ There are two PPAR $\gamma$ isoforms expressed in mouse ${ }^{42}$ and human, ${ }^{43}$ $\gamma 1$ and $\gamma 2$, with different length of N-terminus. PPAR $\gamma 2$ has an additional 28 amino acids at its $\mathrm{N}$-terminus resulting from different promoter use and alternative RNA splicing. ${ }^{42}$ PPAR $\gamma 1$ is expressed in various tissues including adipose tissue, heart, skeletal muscle, liver, kidney, intestines, colon, kidney, pancreas, and spleen. ${ }^{44}$ Whereas PPAR $\gamma 2$ is expressed mainly in adipose tissue. ${ }^{45,46} \mathrm{~A}$ previous study reported that PPAR $\gamma 1$ and PPAR $\gamma 2$ have distinctive activation capacities of insulin, the authors isolated PPAR $\gamma 1$ and PPAR $\gamma 2 \mathrm{~N}$ termini with activation domains, and the activation capacities of PPAR $\gamma 2$ was 5-6 fold greater than that of PPAR $\gamma 1 .{ }^{33} \mathrm{~A}$ better understanding of the molecular structure of PPAR $\gamma$ will provide more opportunities to design ligands to regulate the receptor-mediated biological activities.

\section{Expression of PPAR $y$ in HCC}

The expression of PPAR $\gamma$ in human HCC tissues showed conflicting results from previous studies. Koga et al found there was no significant difference of PPAR $\gamma$ protein expression between HCC tissues and adjacent non-tumorous liver tissues from five patients with $\mathrm{HCV}$-associated HCC. ${ }^{47}$ Interestingly, Schaefer et al found increased expression of PPAR $\gamma$ protein in tumors from 20 HCC patients by immunohistochemistry but no expression in non-tumorous liver distal to the tumor. ${ }^{48}$ In contrast, Yu et al found a significantly
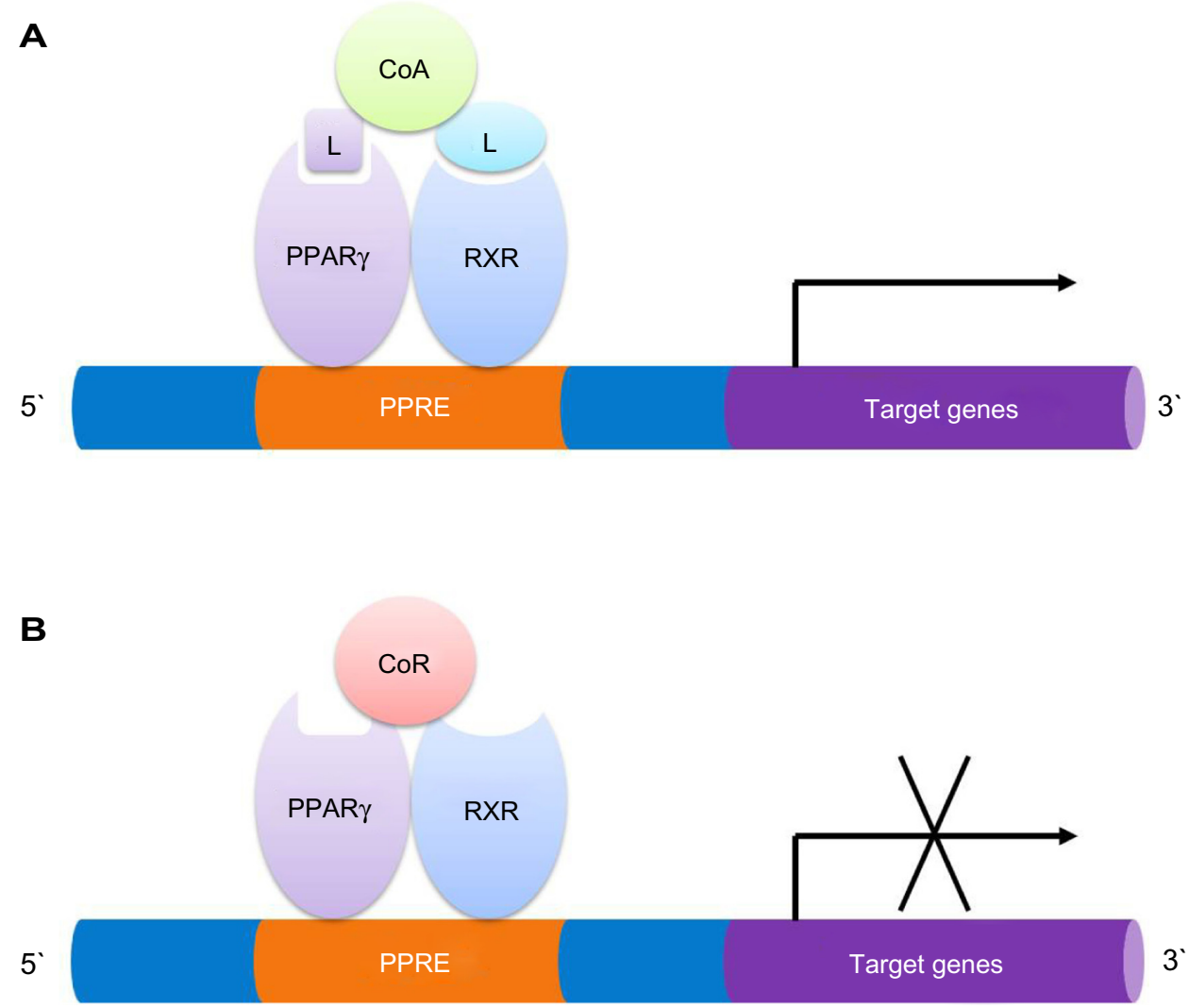

Figure 3 Binding of PPAR $\gamma:$ RXR heterodimers to the PPAR response element.

Notes: In an activation state, once ligand binding has occurred, PPAR $\gamma$ heterodimerizes with RXR and this complex subsequently recruits coactivators, which have histone acetylase activity promoting the transcription for target genes related to lipid and glucose metabolisms as well as inflammation. (A) In an inactive state, PPAR $\gamma$ interacts with the corepressor in the absence of ligands, and this complex has histone deacetylase activity to suppress transcription (B).

Abbreviations: PPAR, peroxisome proliferator-activated receptor; RXR, retinoid X receptor; L, ligand; CoA, coactivator; CoR, corepressor; PPRE, peroxisome proliferatoractivated receptor response element. 
reduced PPAR $\gamma$ expression in HCC tissues compared with adjacent non-tumorous liver in 20 HCC patients, as assessed by Western blot. ${ }^{49}$ More recently, Lin et al found a significant increase in mRNA expression of PPAR $\gamma$ by reverse transcription polymerase chain reaction (RT-PCR) in tumor tissues compared with normal liver in $16 \mathrm{HCC}$ patients. In addition, they also examined the expression of PPAR $\gamma$ in HepG2, Hep3B, Huh-7, and HA22T hepatoma cell lines by RT-PCR and Western blot analyses. The protein level (Hep3B $>$ Huh-7=HA22T $>$ HepG2) of PPAR $\gamma$ did not show exactly the same patterns as compared with mRNA level (Hep3B $>$ HepG2 > Huh-7>HA22T). ${ }^{50}$ Therefore, studies using a larger sample size are required in order to elucidate the functional importance and the clinical significance of PPAR $\gamma$ in HCC. A better understanding of the expression of PPAR $\gamma$ in HCC tissues may help us to elucidate its role in the pathogenesis of HCC.

\section{Functions of PPAR $\gamma$ and PPAR $\gamma$ ligands in HCC Deficiency and overexpression of PPAR $\gamma$ in the progression of HCC}

The role of PPAR $\gamma$ in hepatocarcinogenesis was examined by $\mathrm{Yu}$ et al using PPAR $\gamma$-deficient $\left(\operatorname{PPAR} \gamma^{+-}\right)$and wild-type $\left(\mathrm{PPAR} \gamma^{+/+}\right)$mice in a diethylnitrosamine-induced HCC model. They found increased hepatocellular carcinogenesis in PPAR $\gamma^{+/-}$mice in the diethylnitrosamine-induced HCC model as compared to PPAR $\gamma^{+/+}$mice, and also found that rosiglitazone decreased the incidence of $\mathrm{HCC}$ in PPAR $\gamma^{+/+}$mice compared to PPAR $\gamma^{+/}$mice, indicating that PPAR $\gamma$ acted as a tumor suppressor in hepatocarcinogenesis. ${ }^{51}$ Furthermore, adenovirus-mediated mouse PPAR $\gamma$ overexpression in Hep3B hepatoma cells showed significant inhibition of cell growth, increased cell apoptosis through intrinsic (caspase-3, 7, 9, Bax, and poly[ADP-ribose] polymerase) and extrinsic (Fas, tumor necrosis factor- $\alpha$, and caspase-8) pathways, and cell cycle arrest in G2/M phase through phosphorylation of G2/M phase inhibitors cell division cycle $25 \mathrm{c}(\mathrm{cdc} 25 \mathrm{c})$ and cdc2. In addition, PPAR $\gamma$ overexpression decreased cell viability after rosiglitazone treatment in Hep3B cells. ${ }^{51}$ Recently, overexpression of mouse PPAR $\gamma$ in MHCC97L and BEL7404 hepatoma cells treated with rosiglitazone showed a significant inhibition of migration and invasion through upregulation of E-cadherin and tissue inhibitor of metalloproteinase (TIMP) 3 and downregulation of heparanase (HPSE), matrix metalloproteinase (MMP) 9, and MMP13. ${ }^{52}$ Most recently, adenovirus-mediated PPAR $\gamma$ gene transfer in
Hep3B cells exhibited a dramatic increase of Glu/Asp-rich carboxyl-terminal domain, 2 (CITED2) expression in mRNA and protein levels, resulting in G1-S phase arrest and cell growth inhibition. ${ }^{53}$ However, it will be more interesting if the direct effect of PPAR $\gamma$ ligands on the expression of CITED2 is known in the PPAR $\gamma$ transfected cells. Apparently, PPAR $\gamma$ appears to play a tumor suppressor role in HCC (Figure 4).

\section{PPAR $\gamma$ agonists inhibit cell growth and induce apoptosis in HCC}

Both natural and synthetic PPAR $\gamma$ agonists exhibited growth inhibitory effects in hepatoma cells. TZDs are synthetic PPAR $\gamma$ agonists, used as insulin sensitizers for the treatment of patients with type II diabetes mellitus (DM). PPAR $\gamma$ agonists exert their functions through PPAR $\gamma$-dependent and PPAR $\gamma$-independent pathways. ${ }^{54,55}$ Many studies have reported that TZDs had growth inhibitory effects, such as troglitazone that not only inhibited cell proliferation through increasing p 21 and p $27^{47}$ but also induced apoptosis in hepatoma cells mediated through PI3K-Akt pathway. ${ }^{56}$ Additionally, troglitazone suppressed COX-2 expression

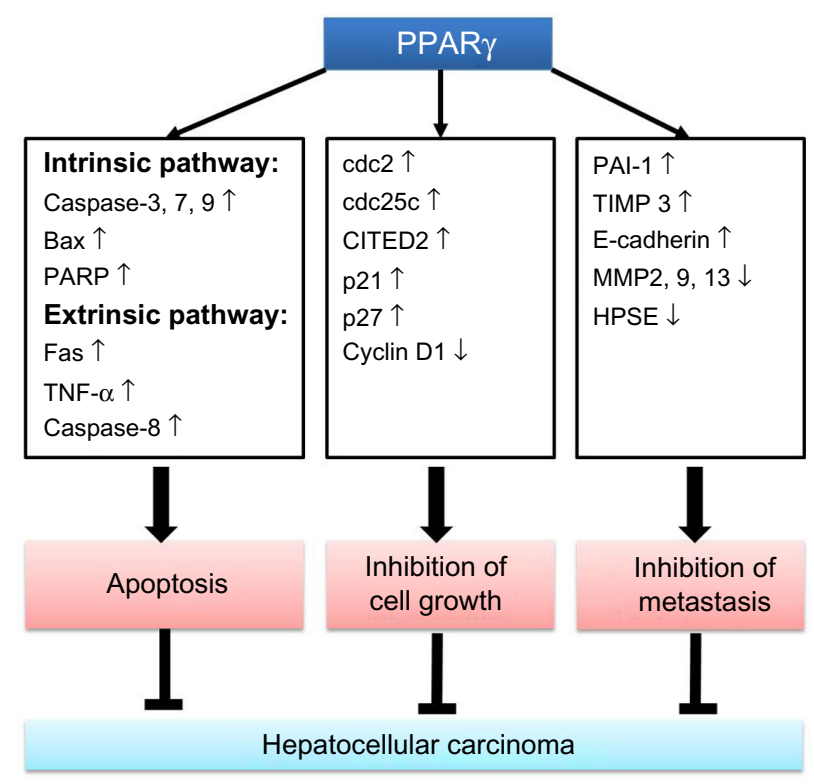

Figure 4 PPAR $\gamma$ signaling in hepatocellular carcinoma.

Notes: Activation of PPAR $\gamma$ triggers apoptosis, and inhibition of cell growth and metastasis in hepatocellular carcinoma. Cell growth inhibition is induced by increased levels of cell cycle arrest-related proteins such as cdc25c, cdc2, p2I, P27, and CITED2, and/or decreased levels of cell cycle promotion-related proteins such as cyclin DI. Apoptosis is induced through intrinsic (increased Bax and PARP, and activated caspase 3,7,9) or extrinsic (increased Fas and TNF- $\alpha$, and activated caspase-8) pathways. Inhibition of metastasis is induced through upregulation of TIMP3, PAI-I, and E-cadherin, and/or downregulation of MMP2, 9, I3, and HPSE.

Abbreviations: PPAR $\gamma$, peroxisome proliferator-activated receptor $\gamma$; PARP, poly(ADP-ribose) polymerase; TNF- $\alpha$, tumor necrosis factor- $\alpha$; cdc, cyclin division cycle; CITED2, Glu/Asp-rich carboxyl-terminal domain, 2; HPSE, heparanase; MMP, matrix metalloproteinase; TIMP, tissue inhibitor of matrix metalloproteinase; PAI-I, plasminogen activator inhibitor-I. 
and increased p27 expression to inhibit cell growth in Hep3B and Huh7 hepatoma cells. ${ }^{49}$ Moreover, rosiglitazone upregulated phosphatase and tensin homolog (PTEN) and downregulated COX-2 expression via PPAR $\gamma$ signaling pathway, leading to the growth inhibition in BEL-7402 and Huh7 cells. ${ }^{57}$ A natural ligand of PPAR $\gamma, 15 \mathrm{~d}_{-} \mathrm{PGJ}_{2}$, induced apoptosis via activation of NFאB in HepG2 and SK-Hep1 cells. ${ }^{58}$ Furthermore, 15d-PGJ ${ }_{2}$ and pioglitazone induced apoptosis possibly through caspase-dependent pathways in HBV-associated cell lines. ${ }^{59}$ It is interesting that HepG2 and Hep3B cells are less invasive as compared to other hepatoma cells such as QGY7703 cells, ${ }^{60}$ further investigation using overexpression of PPAR $\gamma$ in low endogenous PPAR $\gamma$ expression hepatoma cells may provide more valuable information. These results together suggest that activation of PPAR $\gamma$ can induce cell growth inhibition and apoptosis in hepatoma cells.

\section{PPAR $\gamma$ ligands inhibit migration, invasion, and metastasis in HCC}

PPAR $\gamma$ agonists not only have cell growth inhibitory effects but can also inhibit migration, invasion, and metastasis of hepatoma cells. Rosiglitazone inhibited migration through upregulation of PTEN accompanied with decreased phosphorylation of Akt and focal adhesion kinase in hepatoma cell line BEL-7404. ${ }^{61}$ Rosiglitazone and troglitazone inhibited cell migration via upregulation of E-cadherin expression in HepG2 cells. ${ }^{54}$ A recent study demonstrated that activation of PPAR $\gamma$ by rosiglitazone decreased lung metastasis in an orthotopic HCC mouse model. ${ }^{52}$ PPAR $\gamma$ agonist GW1929 decreased invasion ability via upregulation of plasminogen activator inhibitor-1 (PAI-1) in HepG2 and Hepa1-6 cells. However, the invasion ability was restored after pretreatment of PPAR $\gamma$ antagonist GW9662 in Hepa1-6 cells. ${ }^{62}$ Interestingly, PPAR $\gamma$ antagonists GW9662 and T0070907 also inhibited cell migration and invasion through induction of vimentin degradation and inactivation of focal adhesion kinase in poorly differentiated hepatoma cell lines SH-J1 and HLE with high expression of PPAR $\gamma .{ }^{63}$ At present, the detailed mechanism of PPAR $\gamma$ antagonist-induced inhibition of migration in HCC cells is not clear. It is possible that an off target effect exists for PPAR $\gamma$ antagonist in HCC cells, but further experiments using PPAR $\gamma$ knockdown HCC cells will be able to clarify whether this effect is dependent on PPAR $\gamma$ or not. Together, these results clearly showed that both PPAR $\gamma$ agonists and antagonists exhibited an inhibitory role on migration and invasion in hepatoma cells, the detailed molecular mechanism of PPAR $\gamma$ upregulated genes in relation to migration and invasion still needs further investigation.

\section{Honokiol serves as a novel non-adipogenic PPAR $\gamma$ agonist}

Honokiol, a natural biphenolic compound derived from the stem and bark of the plant Magnolia officinalis, exhibits anti-angiogenic and pro-apoptotic activity in cancer cells. ${ }^{64}$ Recent studies found that honokiol, a natural rexinoid, can serve as an RXR agonist in the activation of RXR heterodimers. ${ }^{65,66}$ In addition, honokiol potentiated the PPAR $\gamma$ agonist rosiglitazone induced activation of PPAR $\gamma /$ RXR heterodimers. ${ }^{67}$ Most recently, one study has found that honokiol directly bound to purified PPAR $\gamma$ LBD and served as a novel non-adipogenic PPAR $\gamma$ agonist to stimulate glucose uptake in 3T3-L1 adipocytes. ${ }^{29}$ Additionally, it has been reported that honokiol possesses a wide variety of pharmacological actions with low toxicity such as anti-inflammatory (in lipopolysaccharide-stimulated human monocyte-derived dendritic cells through inhibition of NF- $\mathrm{KB}$ signaling), ${ }^{68}$ antioxidant, ${ }^{69}$ anti-thrombosis, ${ }^{70}$ and neuroprotective. ${ }^{71}$ Moreover, its anti-tumor effects have been found in different types of cancers such as colorectal cancer, ${ }^{72}$ gastric cancer, ${ }^{73}$ and HCC. ${ }^{25-27}$ Honokiol also exhibited an inhibitory role on hepatoma cells by activating the p38 mitogen-activated protein kinase and caspase 3 pathways to induce apoptosis in HepG2 cells, ${ }^{25}$ upregulated Ras GTPase-activating-like protein expression to inhibit HepG2 cell migration. ${ }^{26}$ Recently, it has been reported that honokiol inhibited STAT3 to reduce cell proliferation in HCC cells. ${ }^{27}$ Collectively, results from these studies show that honokiol has the potential to become a novel agent to treat HCC.

\section{Crosstalk between PPAR $\gamma$ and TGF- $\beta$}

Transforming growth factor- $\beta$ (TGF- $\beta$ ) induces cell growth, cell migration, and epithelial to mesenchymal transition as a key driver to promote HCC progression. ${ }^{74}$ There are two mechanisms: intrinsic and extrinsic activities involved in TGF- $\beta$ activation pathway. Once the cell polarity has been lost, acquisition of motile ability, and epithelial to mesenchymal transition are considered as intrinsic changes of the tumor cells. ${ }^{75}$ Extrinsic factors are involved in the changes of tumor microenvironment including angiogenesis, inflammation, and fibroblast activation. ${ }^{74}$ Therefore, TGF- $\beta$ can be considered as a therapeutic target in HCC. Interestingly, PPAR $\gamma$ activation plays an inhibitory role to repress the expression of TGF- $\beta$ via dephosphorylation of zinc finger transcription factor- 9 , and 
this dephosphorylation was induced by PTEN-mediated p70 ribosomal S6 kinase-1 inhibition in mouse fibroblast cells. ${ }^{76}$ However, there is no available information to present on the regulation between PPAR $\gamma$ and TGF- $\beta$ in HCC. Therefore, further investigations are needed to address this issue in HCC. In the pharmacological manipulation, the crosstalk between PPAR $\gamma$ and TGF- $\beta$ can be applied for treating TGF- $\beta$ mediated fibrosis or cancer metastasis.

\section{Interaction between microRNAs and PPAR $\gamma$ in HCC}

The function of microRNAs (miRNAs) in cancers has been studied extensively in recent years. miRNAs are a group of small (20-22 nucleotides) molecule, endogenous, and noncoding RNAs that play an important role in regulating gene expression by targeting mRNAs 3 '-untranslated region for cleavage or translational repression to silence gene expression in eukaryotes. ${ }^{77}$ miRNAs may serve as tumor suppressors or oncogenes which are involved in many biological functions including development, cell proliferation, differentiation, metabolism, and apoptosis. ${ }^{78}$ Many studies have demonstrated that miRNAs are important regulators of gene expression in HCC cells. Recently, it has been reported that PPAR $\gamma$ and $\mathrm{RXR} \alpha$ were regulated by miR-27a in HCC cells to reduce lipid synthesis. ${ }^{79}$ Additionally, miR-122 is liver-specific miRNA which is significantly reduced in HCC, and is correlated with poor prognosis and metastasis. ${ }^{80}$ Most recently, it has been reported that restoration of miR-122 expression in HCC cells reduced AKT3 levels, inhibited cell migration and proliferation, and induced apoptosis, suggesting that miR-122 functions as a tumor suppressor. ${ }^{81}$ It has been reported that some miRNAs could target PPAR $\gamma$ and mediate signal transduction of cellular functions in HCC cells. Interestingly, a recent study clearly showed that miR-122 can be upregulated in hepatoma cells via overexpression of PPAR $\gamma$ by PPAR $\gamma / R X R \alpha$ complex. ${ }^{82}$ These studies together suggest that the reciprocal regulation between miR-122 and PPAR $\gamma$ is worthy of further investigation.

\section{Use of TZDs and the risk of HCC in patients with type II DM}

Several cohort studies have reported that TZDs used in DM patients may influence the risk for HCC. The association between HCC and DM has been reviewed using epidemiological data. A previous study has shown that DM patients have a 2-3 fold increased risk of $\mathrm{HCC}$ from a population based case control study in the USA, despite the presence of other major $\mathrm{HCC}$ risk factors including $\mathrm{HBV}$ or $\mathrm{HCV}$ infections or alcoholic liver disease. ${ }^{3}$ Similarly, results from a population-based cohort study conducted using the Taiwan National Health Insurance Research Database showed an increased incidence of HCC in DM patients. Moreover, this study also showed that the use of TZDs or metformin reduced the risk of HCC development in DM patients. ${ }^{83} \mathrm{~A}$ similar study also showed a significant decrease of liver cancer incidence in type II DM patients treated with rosiglitazone or pioglitazone. ${ }^{84}$ In contrast, a systematic review and meta-analysis using data from Medline, EMBASE, and Web of Science up to August 2012 showed that TZDs did not change the risk of $\mathrm{HCC}$ in patients with type II DM. ${ }^{85}$ Whether this reduced risk is due to control of diabetes which reduces stress on the liver leading to reduced risk of cancer, or due to PPAR related effects is not clear at present and worthy of further investigation. These results together suggest that the underlying functional role of TZDs in HCC development in type II DM patients needs further investigation.

\section{Conclusion}

Current in vitro and in vivo evidence supports the fact that PPAR $\gamma$ activation exerted an inhibitory role on cell growth, migration, and invasion in HCC cells. Most of the studies focused on the effects of TZDs (PPAR $\gamma$ agonist) in HCC cells, while TZDs are currently only used for treatment of type II DM patients. TZDs have known adverse effects such as heart failure. ${ }^{86}$ However, a combination of TZDs with chemotherapeutic drugs for local delivery via transcatheter arterial chemoembolization method may provide an alternative approach for HCC treatment. On the other hand, in view of the recent finding that honokiol has anti-cancer effects, the molecular mechanisms of honokiol-induced cell growth, apoptosis, migration, and invasion needs further investigation in hepatoma cells using in vitro and in vivo models. More importantly, studies focusing on the differential miRNAs expression in $\mathrm{HCC}$, especially miR 122 which was regulated by PPAR $\gamma$ in hepatoma cells, may be a potential target for herbal drugs and PPAR $\gamma$ agonists/antagonists. A better understanding of the molecular regulation on anti-cancer effects in PPAR $\gamma$ mediated signaling may contribute to the development of novel combination therapy for future treatment of HCC.

\section{Disclosure}

The authors have no conflicts of interest in this work.

\section{References}

1. Siegel R, Naishadham D, Jemal A. Cancer statistics, 2012. CA Cancer J Clin. 2012;62(1):10-29.

2. El-Serag HB. Epidemiology of viral hepatitis and hepatocellular carcinoma. Gastroenterology. 2012;142(6):1264-1273. 
3. Davila JA, Morgan RO, Shaib Y, McGlynn KA, El-Serag HB. Diabetes increases the risk of hepatocellular carcinoma in the United States: a population based case control study. Gut. 2005;54(4):533-539.

4. Shau WY, Shao YY, Yeh YC, et al. Diabetes mellitus is associated with increased mortality in patients receiving curative therapy for hepatocellular carcinoma. Oncologist. 2012;17(6):856-862.

5. Farazi PA, DePinho RA. Hepatocellular carcinoma pathogenesis: from genes to environment. Nat Rev Cancer. 2006;6(9):674-687.

6. Wu HC, Santella R. The role of aflatoxins in hepatocellular carcinoma. Hepat Mon. 2012;12(10 HCC):e7238.

7. Yang YY. Can serum cytokines predict hepatic cytokine expression in liver cirrhosis? J Chin Med Assoc. 2011;74(11):485-486.

8. Park EJ, Lee JH, Yu GY, et al. Dietary and genetic obesity promote liver inflammation and tumorigenesis by enhancing IL-6 and TNF expression. Cell. 2010;140(2):197-208.

9. Calle EE, Rodriguez C, Walker-Thurmond K, Thun MJ. Overweight, obesity, and mortality from cancer in a prospectively studied cohort of US adults. $N$ Engl $J$ Med. 2003;348(17):1625-1638.

10. El-Serag HB, Hampel H, Javadi F. The association between diabetes and hepatocellular carcinoma: a systematic review of epidemiologic evidence. Clin Gastroenterol Hepatol. 2006;4(3):369-380.

11. Maggs JR, Suddle AR, Aluvihare V, Heneghan MA. Systematic review: the role of liver transplantation in the management of hepatocellular carcinoma. Aliment Pharmacol Ther. 2012;35(10):1113-1134.

12. Tang $Z Y$. Hepatocellular carcinoma - cause, treatment and metastasis World J Gastroenterol. 2001;7(4):445-454.

13. Flores A, Marrero JA. Emerging Trends in Hepatocellular Carcinoma: Focus on Diagnosis and Therapeutics. Clin Med Insights Oncol. 2014;8 $71-76$.

14. Asghar U, Meyer T. Are there opportunities for chemotherapy in the treatment of hepatocellular cancer? J Hepatol. 2012;56(3):686-695.

15. Shen DW, Lu YG, Chin KV, Pastan I, Gottesman MM. Human hepatocellular carcinoma cell lines exhibit multidrug resistance unrelated to MRD1 gene expression. J Cell Sci. 1991;98(Pt 3):317-322.

16. Llovet JM, Ricci S, Mazzaferro V, et al. Sorafenib in advanced hepatocellular carcinoma. N Engl J Med. 2008;359(4):378-390.

17. Cheng AL, Kang YK, Chen Z, et al. Efficacy and safety of sorafenib in patients in the Asia-Pacific region with advanced hepatocellular carcinoma: a phase III randomised, double-blind, placebo-controlled trial. Lancet Oncol. 2009;10(1):25-34.

18. Worns MA, Koch S, Niederle IM, et al. The impact of patient and tumour baseline characteristics on the overall survival of patients with advanced hepatocellular carcinoma treated with sorafenib. Dig Liver Dis. 2013;45(5):408-413.

19. Yamaguchi R, Yano H, Iemura A, Oqasawara S, Haramaki M, Kojiro M. Expression of vascular endothelial growth factor in human hepatocellular carcinoma. Hepatology. 1998;28(1):68-77.

20. Tsuchiya K, Asahina Y, Matsuda S, et al. Changes in plasma vascular endothelial growth factor at 8 weeks after sorafenib administration as predictors of survival for advanced hepatocellular carcinoma. Cancer. 2014;120(2):229-237.

21. Chen K, Zhang S, Ji Y, et al. Baicalein inhibits the invasion and metastatic capabilities of hepatocellular carcinoma cells via downregulation of the ERK pathway. PLoS One. 2013;8(9):e72927.

22. Xu MX, Zhao L, Deng C, et al. Curcumin suppresses proliferation and induces apoptosis of human hepatocellular carcinoma cells via the wnt signaling pathway. Int J Oncol. 2013;43(6):1951-1959.

23. Zhao JL, Zhao J, Jiao HJ. Synergistic growth-suppressive effects of quercetin and cisplatin on HepG2 human hepatocellular carcinoma cells. Appl Biochem Biotechnol. 2014;172(2):784-791.

24. Yeh $\mathrm{CB}, \mathrm{Hsieh} \mathrm{MJ}$, Lin $\mathrm{CW}$, et al. The antimetastatic effects of resveratrol on hepatocellular carcinoma through the downregulation of a metastasis-associated protease by SP-1 modulation. PLoS One. 2013;8(2):e56661.

25. Deng J, Qian Y, Geng L, et al. Involvement of p38 mitogen-activated protein kinase pathway in honokiol-induced apoptosis in a human hepatoma cell line (hepG2). Liver Int. 2008;28(10):1458-1464.
26. Liang S, Fu A, Zhang Q, et al. Honokiol inhibits HepG2 migration via down-regulation of IQGAP1 expression discovered by a quantitative pharmaceutical proteomic analysis. Proteomics. 2010;10(7): 1474-1483.

27. Rajendran P, Li F, Shanmugam MK, et al. Honokiol inhibits signal transducer and activator of transcription-3 signaling, proliferation, and survival of hepatocellular carcinoma cells via the protein tyrosine phosphatase SHP-1. J Cell Physiol. 2012;227(5):2184-2195.

28. Hu Y, Wang S, Wu X, et al. Chinese herbal medicine-derived compounds for cancer therapy: a focus on hepatocellular carcinoma. J Ethnopharmacol. 2013;149(3):601-612.

29. Atanasov AG, Wang JN, Gu SP, et al. Honokiol: a non-adipogenic PPARgamma agonist from nature. Biochim Biophys Acta. 2013; 1830(10):4813-4819.

30. Wu CW, Farrell GC, Yu J. Functional role of peroxisome-proliferatoractivated receptor gamma in hepatocellular carcinoma. J Gastroenterol Hepatol. 2012;27(11):1665-1669.

31. Desvergne B, Wahli W. Peroxisome proliferator-activated receptors: nuclear control of metabolism. Endocr Rev. 1999;20(5):649-688.

32. Zieleniak A, Wojcik M, Wozniak LA. Structure and physiological functions of the human peroxisome proliferator-activated receptor gamma. Arch Immunol Ther Exp (Warsz). 2008;56(5):331-345.

33. Werman A, Hollenberg A, Solanes G, et al. Ligand-independent activation domain in the $\mathrm{N}$ terminus of peroxisome proliferator-activated receptor gamma (PPARgamma). Differential activity of PPARgamma1 and -2 isoforms and influence of insulin. J Biol Chem. 1997;272(32): 20230-20235.

34. Adams M, Reginato MJ, Shao D, Lazar MA, Chatterjee VK. Transcriptional activation by peroxisome proliferator-activated receptor gamma is inhibited by phosphorylation at a consensus mitogen-activated protein kinase site. J Biol Chem. 1997;272(8):5128-5132.

35. Leff T. AMP-activated protein kinase regulates gene expression by direct phosphorylation of nuclear proteins. Biochem Soc Trans. 2003;31(Pt 1):224-227.

36. Glass CK, Rose DW, Rosenfeld MG. Nuclear receptor coactivators. Curr Opin Cell Biol. 1997;9(2):222-232.

37. Forman BM, Tontonoz P, Chen J, Brun RP, Spiegelman BM, Evans RM. 15-Deoxy-delta 12, 14-prostaglandin J2 is a ligand for the adipocyte determination factor PPAR gamma. Cell. 1995;83(5):803-812.

38. McIntyre TM, Pontsler AV, Silva AR, et al. Identification of an intracellular receptor for lysophosphatidic acid (LPA): LPA is a transcellular PPARgamma agonist. Proc Natl Acad Sci U S A. 2003;100(1): 131-136.

39. Schopfer FJ, Lin Y, Baker PR, et al. Nitrolinoleic acid: an endogenous peroxisome proliferator-activated receptor gamma ligand. Proc Natl Acad Sci U S A. 2005;102(7):2340-2345.

40. Murphy GJ, Holder JC. PPAR-gamma agonists: therapeutic role in diabetes, inflammation and cancer. Trends Pharmacol Sci. 2000;21(12): 469-474.

41. Yau H, Rivera K, Lomonaco R, Cusi K. The future of thiazolidinedione therapy in the management of type 2 diabetes mellitus. Curr Diab Rep. 2013;13(3):329-341.

42. Zhu Y, Qi C, Korenberg JR, et al. Structural organization of mouse peroxisome proliferator-activated receptor gamma (mPPAR gamma) gene: alternative promoter use and different splicing yield two mPPAR gamma isoforms. Proc Natl Acad Sci U S A. 1995;92(17): 7921-7925.

43. Elbrecht A, Chen Y, Cullinan CA, et al. Molecular cloning, expression and characterization of human peroxisome proliferator activated receptors gamma 1 and gamma 2. Biochem Biophys Res Commun. 1996;224(2):431-437.

44. Grygiel-Gorniak B. Peroxisome proliferator-activated receptors and their ligands: nutritional and clinical implications - a review. Nutr J. 2014;13:17.

45. Fajas L, Auboeuf D, Raspe E, et al. The organization, promoter analysis, and expression of the human PPARgamma gene. J Biol Chem. 1997;272(30):18779-18789. 
46. Saraf N, Sharma PK, Mondal SC, Garg VK, Singh AK. Role of PPARg2 transcription factor in thiazolidinedione-induced insulin sensitization. J Pharm Pharmacol. 2012;64(2):161-171.

47. Koga H, Sakisaka S, Harada M, et al. Involvement of p21(WAF1/Cip1), $\mathrm{p} 27$ (Kip1), and p18(INK4c) in troglitazone-induced cell-cycle arrest in human hepatoma cell lines. Hepatology. 2001;33(5):1087-1097.

48. Schaefer KL, Wada K, Takahashi H, et al. Peroxisome proliferatoractivated receptor gamma inhibition prevents adhesion to the extracellular matrix and induces anoikis in hepatocellular carcinoma cells. Cancer Res. 2005;65(6):2251-2259.

49. Yu J, Qiao L, Zimmermann L, et al. Troglitazone inhibits tumor growth in hepatocellular carcinoma in vitro and in vivo. Hepatology. 2006;43(1):134-143.

50. Lin YM, Velmurugan BK, Yeh YL, et al. Activation of estrogen receptors with E2 downregulates peroxisome proliferator-activated receptor gamma in hepatocellular carcinoma. Oncol Rep. 2013;30(6): 3027-3031.

51. Yu J, Shen B, Chu ES, et al. Inhibitory role of peroxisome proliferatoractivated receptor gamma in hepatocarcinogenesis in mice and in vitro. Hepatology. 2010;51(6):2008-2019.

52. Shen B, Chu ES, Zhao G, et al. PPARgamma inhibits hepatocellular carcinoma metastases in vitro and in mice. Br J Cancer. 2012;106(9): 1486-1494.

53. Cheung KF, Zhao J, Hao Y, et al. CITED2 is a novel direct effector of peroxisome proliferator-activated receptor gamma in suppressing hepatocellular carcinoma cell growth. Cancer. 2013;119(6):1217-1226.

54. Lee HJ, Su Y, Yin PH, Lee HC, Chi CW. PPAR(gamma)/PGC-1(alpha) pathway in E-cadherin expression and motility of HepG2 cells. Anticancer Res. 2009;29(12):5057-5063.

55. Uray IP, Rodenberg JM, Bissonnette RP, Brown PH, Mancini MA. Cancer-preventive rexinoid modulates neutral lipid contents of mammary epithelial cells through a peroxisome proliferator-activated receptor gamma-dependent mechanism. Mol Pharmacol. 2012;81(2): 228-238.

56. Mishra P, Paramasivam SK, Thylur RP, Rana A, Rana B. Peroxisome proliferator-activated receptor gamma ligand-mediated apoptosis of hepatocellular carcinoma cells depends upon modulation of PI3Kinase pathway independent of Akt. J Mol Signal. 2010;5:1-17.

57. Cao LQ, Wang XL, Wang Q, et al. Rosiglitazone sensitizes hepatocellular carcinoma cell lines to 5-fluorouracil antitumor activity through activation of the PPARgamma signaling pathway. Acta Pharmacol Sin. 2009;30(9):1316-1322.

58. Okano H, Shiraki K, Inoue H, et al. 15-deoxy-delta-12-14-PGJ2 regulates apoptosis induction and nuclear factor-kappaB activation via a peroxisome proliferator-activated receptor-gamma-independent mechanism in hepatocellular carcinoma. Lab Invest. 2003;83(10):1529-1539.

59. Shim J, Kim BH, Kim YI, et al. The peroxisome proliferator-activated receptor gamma ligands, pioglitazone and 15-deoxy-Delta(12,14)prostaglandin $\mathrm{J}(2)$, have antineoplastic effects against hepatitis B virus-associated hepatocellular carcinoma cells. Int J Oncol. 2010;36(1): 223-231.

60. Zhang NN, Sun QS, Chen Z, Liu F, Jiang YY. Homeostatic regulatory role of Pokemon in NF-kappaB signaling: stimulating both p65 and IkappaBalpha expression in human hepatocellular carcinoma cells. Mol Cell Biochem. 2013;372(1-2):57-64.

61. Zhang W, Wu N, Li Z, Wang L, Jin J, Zha XL. PPARgamma activator rosiglitazone inhibits cell migration via upregulation of PTEN in human hepatocarcinoma cell line BEL-7404. Cancer Biol Ther. 2006;5(8): 1008-1014

62. Pang X, Wei Y, Zhang Y, Zhang M, Lu Y, Shen P. Peroxisome proliferator-activated receptor-gamma activation inhibits hepatocellular carcinoma cell invasion by upregulating plasminogen activator inhibitor-1. Cancer Sci. 2013;104(6):672-680.

63. Kim KR, Choi HN, Lee HJ, et al. A peroxisome proliferator-activated receptor gamma antagonist induces vimentin cleavage and inhibits invasion in high-grade hepatocellular carcinoma. Oncol Rep. 2007;18(4): 825-832.
64. Fried LE, Arbiser JL. Honokiol, a multifunctional antiangiogenic and antitumor agent. Antioxid Redox Signal. 2009;11(5):1139-1148.

65. Kotani H, Tanabe H, Mizukami H, Makishima M, Inoue M. Identification of a naturally occurring rexinoid, honokiol, that activates the retinoid X receptor. J Nat Prod. 2010;73(8):1332-1336.

66. Perez E, Bourguet W, Gronemeyer H, de Lera AR. Modulation of RXR function through ligand design. Biochim Biophys Acta. 2012;1821(1): $57-69$.

67. Kotani H, Tanabe H, Mizukami H, Amagaya S, Inoue M. A naturally occurring rexinoid, honokiol, can serve as a regulator of various retinoid x receptor heterodimers. Biol Pharm Bull. 2012;35(1):1-9.

68. Li CY, Chao LK, Wang SC, et al. Honokiol inhibits LPS-induced maturation and inflammatory response of human monocyte-derived dendritic cells. J Cell Physiol. 2011;226(9):2338-2349.

69. Zhao C, Liu ZQ. Comparison of antioxidant abilities of magnolol and honokiol to scavenge radicals and to protect DNA. Biochimie. 2011;93(10):1755-1760.

70. Teng CM, Chen CC, Ko FN, et al. Two antiplatelet agents from Magnolia officinalis. Thromb Res. 1988;50(6):757-765.

71. Chen C, Lin JK, Liu SH, et al. Characterization of neurotoxic effects of NMDA and the novel neuroprotection by phytopolyphenols in mice. Behav Neurosci. 2010;124(4):541-553.

72. Lai YJ, Lin CI, Wang CL, et al. Expression of survivin and p53 modulates honokiol-induced apoptosis in colorectal cancer cells. J Cell Biochem. Epub June 6, 2014.

73. Liu SH, Shen CC, Yi YC, et al. Honokiol inhibits gastric tumourigenesis by activation of 15-lipoxygenase-1 and consequent inhibition of peroxisome proliferator-activated receptor-gamma and COX-2-dependent signals. Br J Pharmacol. 2010;160(8):1963-1972.

74. Giannelli G, Villa E, Lahn M. Transforming growth factor-beta as a therapeutic target in hepatocellular carcinoma. Cancer Res. 2014;74(7): 1890-1894.

75. Thiery JP. Epithelial-mesenchymal transitions in tumour progression. Nat Rev Cancer. 2002;2(6):442-454.

76. Lee SJ, Yang EK, Kim SG. Peroxisome proliferator-activated receptorgamma and retinoic acid $X$ receptor alpha represses the TGFbeta1 gene via PTEN-mediated p70 ribosomal S6 kinase-1 inhibition: role for Zf9 dephosphorylation. Mol Pharmacol. 2006;70(1):415-425.

77. Bartel DP. MicroRNAs: target recognition and regulatory functions. Cell. 2009;136(2):215-233.

78. Kloosterman WP, Plasterk RH. The diverse functions of microRNAs in animal development and disease. Dev Cell. 2006;11(4):441-450.

79. Shirasaki T, Honda M, Shimakami T, et al. MicroRNA-27a regulates lipid metabolism and inhibits hepatitis $\mathrm{C}$ virus replication in human hepatoma cells. J Virol. 2013;87(9):5270-5286.

80. Tsai WC, Hsu PW, Lai TC, et al. MicroRNA-122, a tumor suppressor microRNA that regulates intrahepatic metastasis of hepatocellular carcinoma. Hepatology. 2009;49(5):1571-1582.

81. Nassirpour R, Mehta PP, Yin MJ. miR-122 regulates tumorigenesis in hepatocellular carcinoma by targeting AKT3. PLoS One. 2013;8(11):e79655.

82. Song K, Han C, Zhang J, et al. Epigenetic regulation of MicroRNA-122 by peroxisome proliferator activated receptor-gamma and hepatitis $\mathrm{b}$ virus $\mathrm{X}$ protein in hepatocellular carcinoma cells. Hepatology. 2013;58(5):1681-1692.

83. Lai SW, Chen PC, Liao KF, Muo CH, Lin CC, Sung FC. Risk of hepatocellular carcinoma in diabetic patients and risk reduction associated with anti-diabetic therapy: a population-based cohort study. Am J Gastroenterol. 2012;107(1):46-52.

84. Chang $\mathrm{CH}$, Lin JW, Wu LC, Lai MS, Chuang LM, Chan KA. Association of thiazolidinediones with liver cancer and colorectal cancer in type 2 diabetes mellitus. Hepatology. 2012;55(5):1462-1472.

85. Singh S, Singh PP, Singh AG, Murad MH, Sanchez W. Anti-diabetic medications and the risk of hepatocellular cancer: a systematic review and meta-analysis. Am J Gastroenterol. 2013;108(6):881-891.

86. Marks DH. Drug utilization, safety and clinical use of Actos and Avandia. Int J Risk Saf Med. 2013;25(1):39-51. 


\section{Publish your work in this journal}

The Journal of Hepatocellular Carcinoma is an international, peerreviewed, open access journal that offers a platform for the dissemination and study of clinical, translational and basic research findings in this rapidly developing field. Development in areas including, but not limited to, epidemiology, vaccination, hepatitis therapy, pathology and molecular tumor classification and prognostication are all considered for publication. The manuscript management system is completely online and includes a very quick and fair peer-review system, which is all easy to use. Visit http://www.dovepress.com/testimonialsphp to read real quotes from published authors.

\footnotetext{
Submit your manuscript here: http://www.dovepress.com/journal-of-hepatocellular-carcinoma-journal
} 